\title{
Antigenic Cross-reactivity of Neisseria Pili: Investigations with Type- and Species-specific Monoclonal Antibodies
}

\author{
By M. VIRJI* AND J. E. HECKELS \\ Department of Microbiology, University of Southampton Medical School, \\ Southampton General Hospital, Southampton SO9 4XY, U.K.
}

(Received 5 April 1983)

\begin{abstract}
Monoclonal antibodies have been produced with both type-specific and broadly cross-reacting properties against the variant pili of Neisseria gonorrhoeae P9. Competitive radioimmunoassays demonstrated that at least three separate epitopes contribute to type-specificity within the strain. ELISA using purified pili from clinical isolates showed that some of the type-specific epitopes are randomly distributed among variants of single strains isolated from different sites in sexual partners. Cross-reacting antibody SM1 recognized an epitope present on all gonococcal isolates. This epitope was also present on a large proportion of meningococci and could be directly demonstrated in CSF from a patient with meningococcal meningitis. Commensal Neisseria and other Gram-negative bacteria tested failed to react. The meningococci which lack the epitope recognized by the antibody SM1 were nevertheless shown by electron microscopy to be pilated, suggesting that pili from meningococci may be antigenically more diverse than those from gonococci.
\end{abstract}

\section{INTRODUCTION}

Pili play an important role in pathogenesis of gonorrhoea mediating attachment to epithelial cells (Mårdh \& Weström, 1976), and interfering with phagocytosis by polymorphonuclear leukocytes (Dilworth et al., 1975). Recent studies have shown that gonococcal pili of a single strain are capable of considerable antigenic variation. Different variants of strain P9 have been isolated which produce one of four pilus types $\alpha, \beta, \gamma, \delta$ with subunit sizes of 19.5, 20.5, 21 and $18.5 \mathrm{kDal}$, respectively (Lambden et al., 1981 a). These pili are antigenically distinct (Virji et al., 1982) and exhibit differences in their ability to attach to different human epithelial cell types (Lambden et al., 1981 b; Heckels, 1982). Pilus-specific antibodies are effective in preventing attachment of the homologous, but not heterologous, variants to the Chang conjunctival cell line (Virji et al., 1982). Furthermore, protection of guinea-pig subcutaneous chambers against infection with strain P9 requires the presence of antibodies directed against each of the variant pilus types present in the challenge inoculum (Lambden et al., 1982). Similar antigenic variations occur during the course of natural infection with isolates from the cervix and urethra of female patients and from the urethra of their male partners, producing pili which differ in subunit molecular weight (Duckworth et al., 1983). These observations indicate that pilus variation must play an important role in the immunobiology of gonococcal infection.

We have sought to study the antigenic relationship between variant pili by use of monoclonal antibodies. A number of antibodies of different specificities were employed for epitope analysis of pili from strain P9 variants (Virji et al., 1983). The study revealed that intra-strain variants shared at least one common epitope in addition to one or more variant-specific antigenic domains. It is unclear if the inter-strain antigenic differences are due to similar structural variations, with each strain being capable of producing an ' $\alpha$ '-type epitope, or whether a further

Abbreviation: CSF, cerebrospinal fluid. 
series of distinct antigenic determinants are present. In the current work we have studied the antigenic diversity of gonococcal pili, using specific monoclonal antibodies to determine the frequency of expression of each epitope in a range of clinical isolates. In addition, we have studied the extent of expression of the common antigenic domain not only on gonococci but also on meningococci and some other Gram-negative bacteria.

\section{METHODS}

Bacterial strains and growth conditions. Variants of $N$. gonorrhoeae strain P9 producing $\alpha, \beta, \gamma$ or $\delta$ pili were grown on a clear typing medium (Lambden $e t$ al., 1979) with the addition of hypoxanthine $\left(3 \cdot 2 \mu \mathrm{g} \mathrm{ml}^{-1}\right)$ and uracil $\left(8 \mu \mathrm{g} \mathrm{ml}^{-1}\right)$, at $37^{\circ} \mathrm{C}$ in an atmosphere of $5 \%(\mathrm{v} / \mathrm{v}) \mathrm{CO}_{2}$. Gonococcal strains directly isolated from the urethra and cervix of female patients and from the urethra of their male partners were grown on the same medium (Duckworth et al., 1983). Other bacteria were obtained as fresh clinical isolates from the Public Health Laboratory, Southampton General Hospital. Neisseria meningitidis was from the cerebrospinal fluid (CSF) of patients with meningococcal meningitis, Escherichia coli from patients with symptomatic urinary-tract infections and other species from a variety of clinical infections. A further group of meningococcal strains was obtained from Dr R. J. Fallon, Ruchhill Hospital, Glasgow. Pilated commensal Neisseria strains were obtained from Dr A. Johnson, Clinical Research Centre, Northwick Park, Harrow, U.K.

Pili. Pili were prepared from a variety of gonococcal strains by repeated cycles of disaggregation in $0.15 \mathrm{M}$ ethanolamine $/ \mathrm{HCl} \mathrm{pH} 10$, followed by precipitation with $\left(\mathrm{NH}_{4}\right)_{2} \mathrm{SO}_{4}$ (Brinton et al., 1978; Lambden et al., $1981 a$ ).

Monoclonal antibodies. The procedure for the production of hybridoma, secreting monoclonal antibodies to gonococcal pili, has been described previously (Virji et al., 1983). Briefly, BALB/C mice were immunized with purified pili or whole pilated variants of strain P9. The spleen cells were fused with BALB/C NS-1 myeloma cell line using $50 \%(\mathrm{w} / \mathrm{v})$ polyetheleneglycol- 4000 (Merck). Hybridoma were screened for the production of anti-pilus antibodies using ELISA and were cloned by limiting dilution. Phenotypically stable hybrids were expanded by growth in culture and approximately $10^{7}$ cells were injected intraperitoneally into BALB/C mice primed with pristane (2,6,10,14-tetramethyl pentadecane; Sigma) to induce ascites. Ascitic fluids were collected and stored at $-70^{\circ} \mathrm{C}$ after centrifugation at $1500 \mathrm{~g}$ for $10 \mathrm{~min}$. Working stocks were stored at $-20^{\circ} \mathrm{C}$ in $50 \%(\mathrm{v} / \mathrm{v})$ glycerol.

Cross-reactivity of monoclonal antibodies. The antigenic cross-reactivity of monoclonal antibodies was determined by ELISA using polystyrene microtitre trays coated with purified pili $\left(1 \mu \mathrm{g} \mathrm{ml}^{-1}\right)$ (Lambden \& Heckels, 1982). Ascitic fluid was serially diluted into PBST [PBS (0.15 M-phosphate buffer, pH 7.2, with $0.15 \mathrm{M}-$ $\mathrm{NaCl}$ ) containing $0.05 \%(\mathrm{v} / \mathrm{v})$ Tween 20]. Antibody binding was detected using rabbit anti-mouse Ig-peroxidase conjugate (Miles, Stoke Poges) with $o$-phenylenediamine as substrate. ELISA titres were calculated as the dilution which gave an increase in $A_{492}$ of $0 \cdot 1 \mathrm{~h}^{-1}$.

Purification of antibodies. Antibodies of IgG class were purified by affinity chromatography on Protein-A Sepharose (Watanabe et al., 1981). Ascitic fluid was applied in 0.14 M-phosphate buffer $\mathrm{pH} 8 \cdot 2$, IgG was eluted with $0.2 \mathrm{M}$ sodium citrate $\mathrm{pH} 4$, and neutralized prior to dialysis. Antibodies of IgM class were purified using immunosorbent columns prepared by coupling rabbit anti-mouse $\mu$ chain antibody (a gift from the Tenovus Research Laboratory, Southampton, U.K.) to CNBr-Sepharose (Pharmacia). Ascitic fluid (0.5 ml) was diluted with an equal volume of PBS, prefiltered through a column $(0.6 \times 5 \mathrm{~cm})$ of Sepharose $4 B$ and the eluate was directly applied to the affinity column $(0.6 \times 5 \mathrm{~cm})$. After washing with PBS, the IgM was eluted with $0.5 \mathrm{M}$ $\mathrm{NH}_{4} \mathrm{OH}$ and samples were collected into $1 \mathrm{M}-\mathrm{Tris} / \mathrm{HCl} \mathrm{pH} 6.8$. Samples containing protein were pooled and dialysed against PBS. The reactivity of the purified antibody against pili was monitored by ELISA to establish that activity was not lost during purification.

Iodination of purified monoclonal immunoglobulins. Purified monoclonal $\mathrm{Ig}$ were labelled with $\mathrm{Na}^{125} \mathrm{I}$ and Iodogen (Pierce, Rockford, Ill., U.S.A.) as described previously (Virji et al., 1983). Unreacted isotope was removed by chromatography on Sephadex G-25 to yield a product with a specific activity of $37 \mathrm{kBq} \mathrm{\mu g}^{-1}$. Protein A (Sigma) was ${ }^{125}$ I-labelled by a similar procedure to specific activity of $100 \mathrm{kBq} \mathrm{\mu g}^{-1}$.

Radioimmunoassay and competitive-binding experiments. Polystyrene microtitre plates were coated with pili under the conditions used for ELISA. Serial dilutions of ascitic fluid in PBS were mixed with an equal volume of PBS containing the predetermined saturating amount of ${ }^{125} \mathrm{I}$-labelled antibody. Antigen-coated plates were washed four times with PBST and the reaction mixture was added. After $16 \mathrm{~h}$ incubation at $4{ }^{\circ} \mathrm{C}$, the plates were washed as before and the radioactive antibody bound was determined by solubilizing with $1 \%(\mathrm{w} / \mathrm{v})$ SDS in $0.1 \mathrm{M}-$ $\mathrm{NaOH}$ and counting in a $\gamma$-counter. The results are expressed as percentage inhibition of binding. [Percentage inhibition $=100 \times\{1-$ (c.p.m. bound in the presence of unlabelled antibody $\div$ c.p.m. bound in the absence of unlabelled antibody)\}].

Similar competition experiments were also carried out using polyclonal rabbit antisera (a gift from Dr G. Schoolnik, Stanford University, California, U.S.A.) raised against fragment CB-2 from strain MS-11 which contains the region common to all gonococcal pili (Schoolnik et al., 1982). 
Screening of bacterial strains for reactivity with antibody SM1. Bacteria grown as described above were scraped from agar plates and suspended in PBS to give $A_{550}$ of approximately $1 \cdot 0$. Samples $(5 \mu \mathrm{l})$ of the suspensions were spotted on to sheets of nitro-cellulose (BA 85; Schleicher \& Schull, Dassel, F.R.G.) and allowed to dry. The bacteria were lysed by placing the sheets on filter paper which had been soaked in $50 \mathrm{mM}-\mathrm{Tris} / \mathrm{HCl} \mathrm{pH} 9 \cdot 5$, containing $1.0 \%(\mathrm{v} / \mathrm{v})$ Nonidet P-40 (Sigma) and incubating at room temperature for $30 \mathrm{~min}$. The sheets were transferred to filter paper soaked in $70 \%(\mathrm{v} / \mathrm{v})$ ethanol, incubated for a further $10 \mathrm{~min}$ and then dried at $37^{\circ} \mathrm{C}$. Excess protein binding of the nitrocellulose was blocked by incubation for $1 \mathrm{~h}$ at $37^{\circ} \mathrm{C}$ with $3 \%(\mathrm{w} / \mathrm{v}) \mathrm{BSA}$ in $10 \mathrm{~mm}$-Tris $/ \mathrm{HCl} \mathrm{pH} 7.4$ containing $0.9 \%(\mathrm{w} / \mathrm{v}) \mathrm{NaCl}$. After drying, the sheets were rinsed with $50 \mathrm{mM}-\mathrm{Tris} / \mathrm{HCl}$ pH 7.4 containing $150 \mathrm{~mm}-\mathrm{NaCl}, 5 \mathrm{~mm}$-EDTA, $0.25 \%(\mathrm{w} / \mathrm{v})$ gelatin and $0.05 \%(\mathrm{v} / \mathrm{v})$ Nonidet P-40 (B buffer), then incubated at room temperature with ascitic fluid diluted $1: 100$ in $\mathrm{B}$ buffer. They were then washed with $\mathrm{B}$ buffer, and incubated with ${ }^{125} \mathrm{I}$-labelled protein $\mathrm{A}$ in B buffer $\left[10^{6} \mathrm{c}\right.$.p.m. (ml Protein A) ${ }^{-1}$; specific activity $100 \mathrm{kBq}$ $\mu \mathrm{g}^{-1}$ ]. Finally, the sheets were extensively washed with $B$ buffer and air-dried. Immunological reactivity was detected following overnight autoradiography using Kodak X-Omat AR film and an X-Omatic regular intensifying screen.

SDS-PAGE and immunoblotting. Whole-cell bacterial lysates were subjected to SDS-PAGE at a concentration of $5 \mu \mathrm{g}$ protein per track on gels $(1 \times 160 \times 110 \mathrm{~mm})$ containing linear gradients of $10-25 \%(w / v)$ acrylamide (Heckels, 1981). The separated proteins were electrophoretically transferred to nitrocellulose sheets (BA 85; Schleicher \& Schull, Dassel, F.R.G.) as described previously (Virji et al., 1983). Excess protein-binding capacity was blocked using bovine serum albumin and the sheets were reacted sequentially with monoclonal antibody and ${ }^{125}$ I-labelled protein $\mathrm{A}$ as described above.

Electron microscopy. Meningococci were examined for pili after negative staining with uranyl acetate on Formvar-carbon grids as described by Lambden et al. $(1981 b)$.

\section{RESULTS}

\section{Cross-reactivity of monoclonal antibodies}

The monoclonal antibodies used in this study are shown in Table 1. They were raised by immunization with strain P9 pili and several have previously been utilized for epitope analysis on the $\alpha, \beta, \gamma$ and $\delta$ pili of the homologous strain (Virji et al., 1983). In order to investigate their inter-strain reactivity, the antibodies were reacted in ELISA with purified pili from gonococcal variants of three groups of consorts in addition to strain P9. The results are presented in Table 1. Antibodies SM3, 4, 5 and 8 were highly specific and reacted only with a single P9 pilus type, whereas antibodies SM6 and 7 showed very limited cross-reactivity and only within strain P9. Two further types of cross-reactivity were seen. Antibodies SM1 and 2 recognized epitopes present on all pilus types although, as previously reported with P9 pili (Virji et al., 1983), SM2 showed greater variation in avidity against different pilus types. On the other hand, antibodies SM10 and SM11 recognized epitopes present on pili from a limited number of clinical variants in addition to strain P9. Antibody SM11 cross-reacted significantly only with $\alpha$ pili and pili of isolate SU72 from a male patient, but not with pili from either variant of the same strain isolated from the female partner. In contrast, antibody SM10 reacted strongly with $\alpha$ pili and with decreasing activity against the homologous variants in the order $\beta>\delta \gg \gamma$. It also reacted strongly with SU50 pili but not with the other pili from that group.

\section{Competitive radioimmunoassay}

The location of the binding sites of antibodies SM10 and SM11 in relation to the other $\alpha$ reactive antibodies was investigated by competitive radioimmunoassay using a panel of labelled antibodies (Table 2). Antibody SM10 lost activity on iodination and could not therefore be used in the labelled form. On $\alpha$ pili, antibodies SM 10 and 11 bind to distinct sites, since SM10 did not inhibit the binding of labelled SM11. In addition, these antibodies do not compete with SM1, SM3 or SM4. The latter two antibodies appear to share an $\alpha$-specific epitope as has been reported earlier (Virji et al., 1983). Furthermore, the binding of labelled SM11 is significantly inhibited by the $\alpha$-specific antibody SM5 suggesting a close association between the two binding sites.

On SU50 and SU72 pili, only a limited number of investigations was possible, since specific antibodies directed towards these pili are not available. However, the results show a complete lack of competition between the broadly cross-reacting SM1 and the antibodies SM10 and SM11 on their respective pilus types (Table 2). Thus as on $\alpha$ pili, the specific antibodies appear to bind away from the pilus-conserved region. 
Table 1. Cross-reactivity of monoclonal antibodies with gonococcal pili

Pili purified from variants of strain P9 and from three groups of consorts were used in ELISA to determine the extent of cross-reactivity of monoclonal anti-pilus antibodies, raised by immunization with $\mathrm{P} 9$ pili. Fresh clinical isolates were from the urethra of male patients (M) and their female partners (F); urethra (U) and cervix (C). Figures are expressed as titre $\times 10^{-3} ;-$ represents a titre $<0.05$.

\begin{tabular}{|c|c|c|c|c|c|c|c|c|c|c|c|c|c|}
\hline \multirow[b]{3}{*}{ Clone } & \multirow{3}{*}{$\begin{array}{l}\text { Antibody } \\
\text { isotype }\end{array}$} & \multicolumn{4}{|c|}{ Strain P9 } & \multicolumn{2}{|c|}{ Group 1} & \multicolumn{3}{|c|}{ Group 2} & \multicolumn{3}{|c|}{ Group 3} \\
\hline & & $\alpha$ & $\beta$ & $\gamma$ & $\delta$ & M & F & $\mathbf{M}$ & & & $\mathbf{M}$ & & \\
\hline & & & & & & SU70 & SU71C & SU50 & SU51U & SU51C & SU72 & SU73C & SU73U \\
\hline SM 1 & $\operatorname{IgG} 2 \mathrm{a}$ & 2900 & 2500 & 2250 & 1300 & 400 & 1600 & 1600 & 2500 & 1100 & 1100 & 1600 & 400 \\
\hline SM 2 & $\operatorname{IgG} 3$ & 3770 & 850 & 990 & 76 & 630 & 200 & 17 & 2900 & 820 & 1300 & 1300 & 1200 \\
\hline SM 3 & IgG1 & 4050 & - & - & - & - & - & - & - & - & - & -- & - \\
\hline SM 4 & IgM & 475 & - & - & - & - & $\ldots$ & - & - & - & - & - & - \\
\hline SM 5 & IgG3 & 250 & - & - & - & - & - & - & - & - & - & - & - \\
\hline SM 6 & IgG1 & - & - & 1500 & 1250 & - & - & - & - & - & - & - & - \\
\hline SM 7 & IgM & - & - & 190 & 190 & - & - & - & - & - & - & - & - \\
\hline SM 8 & $\lg 2 a$ & - & - & 200 & - & - & - & - & - & - & - & $\ldots$ & - \\
\hline SM10 & IgM & 266 & 120 & 1 & 62 & - & - & 226 & - & - & $0 \cdot 1$ & - & - \\
\hline SM11 & IgM & 164 & $0 \cdot 1$ & - & 0.5 & - & $0 \cdot 1$ & - & -- & - & 100 & -- & - \\
\hline
\end{tabular}

Table 2. Epitope analysis by competitive radioimmunoassay

The binding sites for antibodies SM10 and SM11 were investigated by competitive radioimmunoassays using antibody containing ascitic fluids at 1:50 dilution. Mean values from three experiments are shown and the homologous competition is underlined. Controls containing ascitic fluid without antipilus activity showed less than $15 \%$ inhibition of specific binding. - Not tested since there was no reactivity between these pairs of antigen and antibody.

\begin{tabular}{|c|c|c|c|c|c|c|c|c|}
\hline \multirow{2}{*}{$\begin{array}{l}\text { Pilus } \\
\text { antigen }\end{array}$} & \multirow{2}{*}{$\begin{array}{l}10^{-3} \times \\
\text { Mol. wt }\end{array}$} & \multirow{2}{*}{$\begin{array}{l}\text { Iodinated } \\
\text { antibody }\end{array}$} & \multicolumn{6}{|c|}{ by competing antibody: } \\
\hline & & & SM1 & SM3 & SM4 & SM5 & SM10 & SM11 \\
\hline \multirow{4}{*}{$\alpha$} & \multirow{4}{*}{$19 \cdot 5$} & (SM1 & 94 & 10 & 5 & 9 & 2 & 3 \\
\hline & & SM3 & $\overline{0}$ & 87 & 76 & 0 & 10 & 6 \\
\hline & & SM4 & 8 & $\overline{64}$ & $\underline{83}$ & 0 & 0 & 14 \\
\hline & & | SM11 & 12 & 22 & $\overline{24}$ & 72 & 17 & $\underline{86}$ \\
\hline SU50 & 17.5 & SM1 & $\underline{90}$ & - & - & - & 14 & - \\
\hline \multirow{2}{*}{ SU72 } & \multirow{2}{*}{$19 \cdot 0$} & SM1 & $\underline{93}$ & - & - & - & - & 9 \\
\hline & & SM11 & $\overline{14}$ & - & - & - & - & 85 \\
\hline
\end{tabular}

Table 3. Competitive inhibition of binding of monoclonal antibody SMI

The binding site for antibody SM1 was investigated by competitive radioimmunoassay using labelled SM1 and polyclonal rabbit antiserum raised against cyanogen bromide fragment CB-2. Mean values from the two experiments are shown.

\begin{tabular}{|c|c|c|c|c|}
\hline \multirow{2}{*}{$\begin{array}{c}\text { Competing } \\
\text { antibody }\end{array}$} & \multirow[b]{2}{*}{ Dilution } & \multicolumn{3}{|c|}{ Percentage inhibition of binding of SM-1 with: } \\
\hline & & $\alpha$ Pili & SU72 Pili & MS11 Pili \\
\hline $\begin{array}{l}\text { SM-1 } \\
\text { anti-CB-2 }\end{array}$ & $\begin{array}{c}1: 50 \text { (Ascites) } \\
1: 5 \text { (Serum) }\end{array}$ & $\begin{array}{l}92 \\
86\end{array}$ & $\begin{array}{l}89 \\
87\end{array}$ & $\begin{array}{l}90 \\
96\end{array}$ \\
\hline
\end{tabular}

Polyclonal antiserum to the common gonococcal pilus fragment (CB2) was also used in competitive radioimmunoassay to investigate the binding site of the broadly cross-reacting monoclonal antibody SM1. As shown in Table 3, the presence of anti-CB-2 inhibited the binding of SM1 on three different gonococcal pili : $\alpha$, SU72 and the homologous pilus MS11, indicating that antibody SM1 binds to an epitope present in fragment CB-2. 


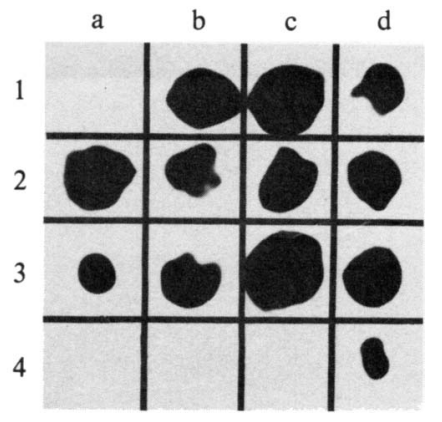

Fig. 1. Reaction of monoclonal antibody SM1 with whole-cell bacterial lysates. Suspensions were spotted on to nitrocellulose, lysed and reacted with antibody followed by ${ }^{125}$ I-labelled Protein A. Strains tested were: 1 a, P9-1 (non-pilated); $1 \mathrm{~b}, \mathrm{P9}-2$ ( $\alpha$ pili); $1 \mathrm{c}-2 \mathrm{~d}$, fresh gonococcal isolates; $3 \mathrm{a}-\mathrm{d}$, fresh meningococcal isolates; $4 \mathrm{a}$, Neisseria subflava $19243 ; 4 \mathrm{~b}, E$. coli; $4 \mathrm{c}, P$. aeruginosa; $4 \mathrm{~d}$, CSF from patient with meningococcal meningitis.

\section{Table 4. Cross-reactivity of clone SMI with several bacterial species}

Reactivity was determined by autoradiography after reaction with SM-1 and ${ }^{125}$ I-Protein A as shown in Fig. 1.

$\begin{array}{lcc}\text { Species } & \begin{array}{c}\text { No. of strains } \\ \text { tested }\end{array} & \begin{array}{c}\text { Positive } \\ \text { reaction }\end{array} \\ \text { N. gonorrhoeae } & 51 & 51 \\ \text { N. meningitidis } & 10^{*} & 9 \\ & 10 \dagger & 7 \\ \text { Other Neisseria } \text { species } & 14 & 0 \\ \text { E. coli } & 11 & 0 \\ P . \text { aeruginosa } & 10 & 0 \\ \text { H. influenzae } & 5 & 0\end{array}$

* Fresh clinical isolates from Southampton General Hospital.

† Strains from the meningococcal reference laboratory, Ruchhill Hospital, Glasgow, which had been subjected to several subcultures.

\section{Reactivity of clone SM-I with a variety of bacterial species}

The reactivity of the monoclonal antibody SM1 with gonococcal isolates was investigated initially by a procedure which employed 'colony blotting' on to nitrocellulose filters (Meyer et al., 1982). This method was found to be unsuitable for large-scale screening of different strains. Therefore, an alternative procedure was developed for rapid analysis of antibody-reactivity against various bacteria. Drops of bacterial suspensions were placed on nitrocellulose sheets, lysed with detergent and sequentially reacted with SM1 antibody and ${ }^{125}$ I-labelled Protein A. A typical autoradiograph is shown in Fig. 1. Fresh gonococcal isolates reacted strongly but laboratory-selected $\mathbf{P}^{-}$variants showed no antibody binding. Table 4 summarizes the data from several experiments with different bacterial species. All the gonococcal isolates tested gave a positive reaction, as did nine out of ten fresh meningococcal isolates and seven out of ten meningococci in another group which had been obtained from a reference laboratory. Electron microscopy of negatively stained meningococci showed the presence of pili even on the nonreacting strains. No reaction was seen with $E$. coli, $H$. influenzae and Pseudomonas species or with commensal Neisseria, including several which had previously been shown to be pilated (McGee et al., 1977).

A similar procedure was applied to the CSF of a patient from whom one of the meningococcal strains was isolated. Again positive reaction with SM1 was detected (Fig. 1). 


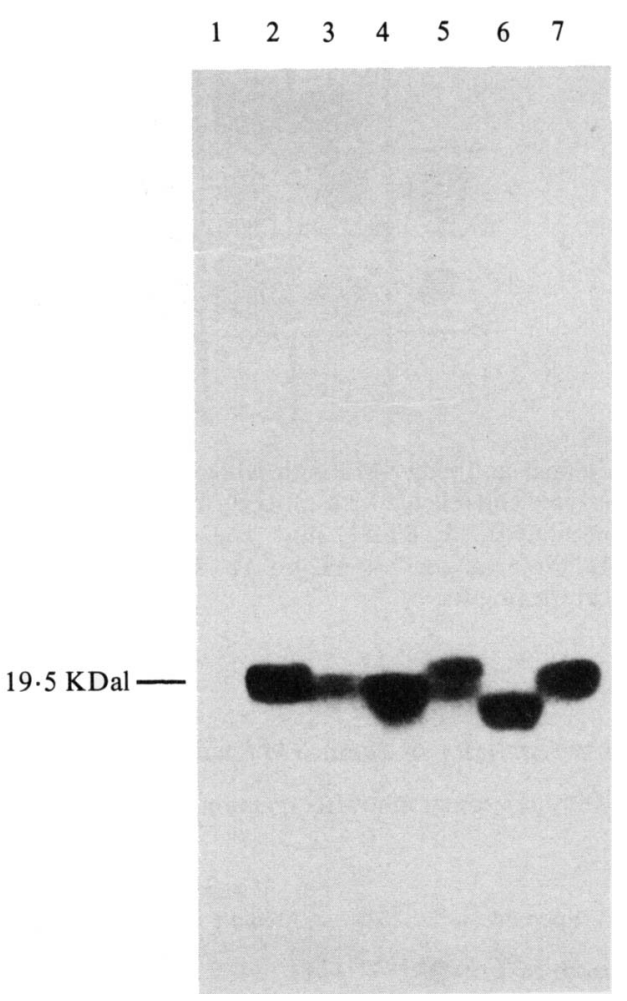

Fig. 2. Immunoblotting with antibody SM-1 after SDS-PAGE of whole-cell bacterial lysates. Strains tested were: gonococcal strain P9-1 (track 1); P9-2 (track 2) and fresh meningococcal isolates (tracks 3-7).

\section{Demonstration of cross-reacting pili on meningococci}

Whole cell lysates of meningococci were subjected to SDS-PAGE, blotted on to nitrocellulose sheets and reacted with antibody SM1. After reaction with ${ }^{125}$ I-labelled protein A and autoradiography, distinct pilus bands could be seen on each of the tracks (Fig. 2) with molecular weights in the region $16 \cdot 8 \mathrm{~K}-19 \cdot 0 \mathrm{~K}$. In several cases at least two polypeptides reacted with the antibody.

\section{DISCUSSION}

Previous studies with monoclonal antibodies SM1-8 showed that pili from variants of strain P9 contained several distinct antigenic sites (Virji et al., 1983). At least one of these sites is shared by all P9 pili and, in addition, they appeared to possess more than one type-specific epitope. In the present study, this is clearly demonstrated by the use of additional $\alpha$-reactive antibodies. Competitive radioimmunoassays showed that antibodies SM3 and SM4 compete with each other for the same or closely positioned epitopes. Similarly SM5 and SM11 compete for other binding sites on $\alpha$-pili which cannot be identical since the antibodies show different specificities for other pili. In addition, SM10 recognizes a further $\alpha$-pilus epitope. These observations suggest that the variable region of $\alpha$-pili contains a mosaic of epitopes which together contribute to the ' $\alpha$ '-specificity of the pili. The epitopes must be present on a single pilus type, since $\alpha$-pili, affinity-purified using antibody SM5, also bind antibodies SM1, 2, 3, 4, 10 and 11 (unpublished observation).

The genetic mechanisms which control pilus variation are unclear although the switch from the $\mathrm{P}^{+}$to the $\mathrm{P}^{-}$state has been shown to involve chromosomal rearrangement (Meyer et al., 
1982). One possible model for pilus variation would involve a limited number of genes widely distributed amongst gonococcal strains with each strain capable of switching to production of a pilus corresponding to the $\alpha, \beta, \gamma$ or $\delta$ of strain P9. Our data suggests that the situation is considerably more complex than this. Six out of the eight antibodies exhibiting P9-type specificity failed to react with pili from any of the other strains tested. However, antibodies SM10 and SM11, which react with epitopes present on $\alpha$-pili, show cross-reactivity with entirely different pili from other strains. In addition, these pili with epitopes in common have quite different subunit molecular weights. These observations suggest that pilus-specificity is determined by a particular combination from a large number of possible epitopes, some of which may be randomly shared among other strains.

In addition to their complex antigenic heterogeneity, gonococcal pili have common antigenic determinants. The conserved epitopes on P9 pili previously detected with antibodies SM1 and SM2 (Virji et al., 1983) are shared with other gonococci. These observations are consistent with the primary sequence data obtained from fragments generated on cyanogen bromide cleavage of gonococcal pili (Buchanan et al., 1982; Schoolnik et al., 1982). The short peptide CB-1 generated from the first seven $\mathrm{N}$-terminal amino-acids showed complete homology between gonococci, meningococci and Pseudomonas aeruginosa. Of the two larger fragments, CB-2 showed considerable homology between gonococci and meningococci while CB-3 contained sequences unique to the specific pilus type. Binding of antibody SM1 is inhibited by antisera raised against CB-2 suggesting that the common epitope recognized by SM1 is located in this common peptide. Colony blotting showed that it is also present on all gonococci but not on E. coli or P. aeruginosa.

The situation with meningococci is more complex. Previous studies with a monoclonal antibody raised against meningococci identified an epitope present on both meningococcal and gonococcal pili (Brinton et al., 1982). In the current work, the majority of strains reacted with SM1, and pili could be directly detected by the antibody in the CSF of a patient with meningococcal meningitis. However, a few strains failed to react even though the presence of pili could be detected by electron microscopy. The importance of pili in meningococcal virulence is less well documented than that of gonococcal pili in gonorrhoea, although pili have been detected on meningococci present in CSF of a patient with meningitis (Stephens et al., 1982). The differential reactivity of SM1 with meningococci raises two intriguing possibilities. SM1 recognizes an epitope in the conserved region which contains cell-surface-receptor activity (Schoolnik et al., 1982; Gubish et al., 1982), perhaps suggesting that meningococci which produce pili with altered antibody-binding properties may also have different cell-receptor specificity. Secondly, the detection on SDS-PAGE of more than one pilin band reacting with SM1 suggests that meningococcal pili, like gonococcal pili, are capable of antigenic variation during the course of the natural infection. The significance of these observations to an understanding of meningococcal pathogenesis must await further studies.

We are grateful to Professor P. J. Watt for his interest and encouragement, to Dr M. E. Ward for assistance with electronmicroscopy and to $\mathrm{Dr}$ G. Schoolnik for providing antisera. This work was supported by an MRC Programme Grant.

\section{REFERENCES}

Brinton, C. C., Bryan, J., Dillon, J.-A., Guerina, N., Jacobson, L. J., LABIK, A., LeE, S., LeVine, A., Lim, S., McMichael, J., Polen, S., Rogers, K., To, A. C.-C. \& To, S. C.-M. (1978). Uses of pili in gonorrhea control: role of bacterial pili in disease, purification and properties of gonococcal pili, and progress in the development of a gonococcal pilus vaccine for gonorrhea. In Immunobiology of Neisseria gonorrhoeae, pp. 155-178. Edited by G. F. Brooks, E. C. Gotschlich, K. K. Holmes, W. D. Sawyer \& F. E. Young. Washington, D.C.: American Society for Microbiology.

Brinton, C. C., Wood, S. W., Brown, A., Labik, A. M., Bryan, J. R., Lee, S. W., Polen, S. E.,
Tramont, E. C., SAdoff, J. \& Zollinger, W. (1982). The development of a Neisseria pilus vaccine for gonorrhoea and meningococcal meningitis. In Seminars in Infectious Disease, vol. IV, Bacterial Vaccines, pp. 140-159. Edited by L. Weinstein, B. N. Fields, J. B. Robbins, J. C. Hill \& G. Sadoff. New York: Thieme-Stratton.

Buchanan, T. M., Siegel, M. S., Chen, K. C. S. \& Pearce, W. A. (1982). Development of a vaccine to prevent gonorrhoea. In Seminars in Infectious Disease, vol. IV, Bacterial Vaccines, pp. 160-164. Edited by L. Weinstein, B. N. Fields, J. B. Robbins, J. C. Hill \& G. Sadoff. New York: Thieme-Stratton.

Dilworth, J. A., Hendley, J. O. \& Mandell, G. L. 
(1975). Attachment and ingestion of gonococci by human neutrophils. Infection and Immunity 11, 512516.

Duckworth, M., JACKson, D., ZAK, K. \& Heckels, J. E. (1983). Structural variations in pili expressed during gonococcal infection. Journal of General Microbiology 129, 1593-1596.

Gubish, E. R., Chen, K. C. S. \& Buchanan, T. M. (1982). Attachment of gonococcal pili to lectinresistant clones of Chinese hamster ovary cells. Infection and Immunity 37, 189-194.

HeCKELS, J. E. (1981). Structural comparison of Neisseria gonorrhoeae outer membrane proteins. Journal of Bacteriology 145, 736-742.

HeCkels, J. E. (1982). The role of surface proteins in the adhesion of Neisseria gonorrhoeae. In Microbiology 1982, pp. 301-304. Edited by D. Schlessinger. Washington, D.C.: American Society for Microbiology.

LAMBden, P. R. \& Heckels, J. E. (1982). Synthesis of immunogenic oligosaccharide-protein conjugates from the lipopolysaccharide of Neisseria gonorrhoeae P9. Journal of Immunological Methods 48, 233-240.

Lambden, P. R., Heckels, J. E., James, L. T. \& WatT, P. J. (1979). Variations in surface protein associated with virulence properties in opacity types of Neis seria gonorrhoeae. Journal of General Microbiology 114, 305-312.

Lambden, P. R., Heckels, J. E., McBride, H. \& WATT, P. J. (1981 $a)$. The identification and isolation of novel pilus types produced by variants of Neisseria gonorrhoeae $\mathrm{P9}$ following selection in vivo. FEMS Microbiology Letters 10, 339-341.

Lambden, P. R., Robertson, J. N. \& Watt, P. J. $(1981 b)$. The preparation and properties of $\alpha$ and $\beta$ pili from variants of Neisseria gonorrhoeae P9. Journal of General Microbiology 124, 109-117.

LAMBden, P. R., Heckels, J. E. \& WATT, P. J. (1982). Effect of anti-pilus antibodies on survival of gono- cocci within guinea pig subcutaneous chambers. Infection and Immunity 38, 27-30.

MÅRDH, P. A. \& WESTRÖM, L. (1976). Adherence of bacteria to vaginal epithelial cells. Infection and Immunity 13, 661-666.

McGee, Z. A., Dourmashkin, R. R., Gross, J. G., Clark, J. B. \& Taylor-Robinson, D. (1977). Relationship of pili to colonial morphology among pathogenic and nonpathogenic species of Neisseria. Infection and Immunity 15, 594-600.

Meyer, T. F., Mlawer, N. \& So, M. (1982). Pilus expression in Neisseria gonorrhoeae involves chromosomal rearrangement. Cell 40, 45-52.

Schoolnik, G. K., TAI, J.-Y. \& Gotschlich, E. C. (1982). The human erythrocyte binding domain of gonococcal pili. In Seminars in Infectious Disease, vol. IV, Bacterial Vaccines, pp. 172-180. Edited by L. Weinstein, B. N. Fields, J. B. Robbins, J. C. Hill \& G. Sadoff. New York: Thieme-Stratton.

STEPHENS, D. S., EdWARds, K. M., Morris, F. \& McGee, Z. A. (1982). Pili and outer membrane appendages on Neisseria meningitidis in the cerebrospinal fluid of an infant. Journal of Infectious Diseases 146, 568.

VirJi, M., Everson, J. S. \& Lambden, P. R. (1982). Effect of anti-pilus antisera on virulence of variants of Neisseria gonorrhoeae for cultured epithelial cells. Journal of General Microbiology 128, 1095-1100.

VirJi, M., Heckels, J. E. \& Watt, P. J. (1983). Monoclonal antibodies to gonococcal pili: Studies on antigenic determinants on pili from variants of strain P9. Journal of General Microbiology 129, 19651973.

Watanabe, M., Ishil, T. \& Nariuchi, H. (1981). Fractionation of $\operatorname{IgG} 1$, IgG2a, IgG2b, and IgG3 immunoglobulins from mouse serum by Protein ASepharose column chromatography. Japanese Journal of Experimental Medicine 51, 65-70. 